\title{
Electrochemical Oxidation of EDTA in Nuclear Wastewater Using Platinum Supported on Activated Carbon Fibers
}

\author{
Bo Zhao ${ }^{1,2}$, Wenkun Zhu ${ }^{1,3, *}$, Tao Mu ${ }^{4}$, Zuowen $\mathrm{Hu}^{4}$ and Tao Duan ${ }^{1,3}$ \\ 1 Key Subject Laboratory of National Defense for Radioactive Waste and Environmental Security, \\ Southwest University of Science and Technology, Mianyang 621010, China; bozhao@swust.edu.cn (B.Z.); \\ duantao112@163.com (T.D.) \\ 2 School of Life Science and Engineering, Southwest University of Science and Technology, \\ Mianyang 621010, China \\ 3 Sichuan Civil-Military Integration Institute, Mianyang 621010, China \\ 4 China Academy of Engineering Physics, Mianyang 621000, China; mutao1224@126.com (T.M.); \\ huzuowen1979@sina.com (Z.H.) \\ * Correspondence: hnw57@ustc.edu.cn
}

Received: 15 June 2017; Accepted: 18 July 2017; Published: 21 July 2017

\begin{abstract}
A novel Pt/ACF (Pt supported on activated carbon fibers) electrode was successfully prepared with impregnation and electrodeposition method. Characterization of the electrodes indicated that the Pt/ACF electrode had a larger effective area and more active sites. Electrochemical degradation of ethylenediaminetetra-acetic acid (EDTA) in aqueous solution with $\mathrm{Pt} / \mathrm{ACF}$ electrodes was investigated. The results showed that the $3 \% \mathrm{Pt} / \mathrm{ACF}$ electrode had a better effect on EDTA removal. The operational parameters influencing the electrochemical degradation of EDTA with $3 \% \mathrm{Pt} / \mathrm{ACF}$ electrode were optimized and the optimal removal of EDTA and chemical oxygen demand (COD) were $94 \%$ and $60 \%$ after $100 \mathrm{~min}$ on condition of the electrolyte concentration, initial concentration of EDTA, current density and initial value of $\mathrm{pH}$ were $0.1 \mathrm{~mol} / \mathrm{L}, 300 \mathrm{mg} / \mathrm{L}, 40 \mathrm{~mA} / \mathrm{cm}^{2}$ and 5.0, respectively. The degradation intermediates of EDTA in electrochemical oxidation with $3 \%$ $\mathrm{Pt} / \mathrm{ACF}$ electrode were identified by gas chromatography-mass spectrum (GC-MS).
\end{abstract}

Keywords: ethylenediaminetetra-acetic acid; electrochemical oxidation; Pt/ACF electrode; degradation intermediates

\section{Introduction}

The main purpose for considering the use of the decontamination techniques in the nuclear installation out of commission is removing the contamination from equipment and to reduce dose levels. Ethylenediaminetetra-acetic acid (EDTA) is an efficient chelating agent widely used in industrial, agricultural and pharmaceutical applications, among others. It is also an important decontaminating agent in the nuclear industry. The presence of EDTA in radioactive liquid waste made it difficult to treat because: (1) EDTA of ionic state will form to complex with radioactive nuclide and this made it difficult to be separated. (2) The existence of EDTA in the radioactive wastewater reduced chemisorption of radioactive nuclide and accelerated its migration rate in ground water, soil and surface water [1]. (3) The degradation of EDTA in radioactive wastewater will generate $\mathrm{CO}, \mathrm{CO}_{2}, \mathrm{H}_{2}$ and these gases decreased stability of wastewater [2]. The conventional methods to treat EDTA in radioactive wastewater such as incineration, pyrolysis, Fenton oxidation, wet oxidation [3], ultraviolet light and ozone oxidation [4], are low efficiency and require complicated devices. Nowadays, electrochemical oxidation systems have been proven to be very effective to treat a variety of organic wastewaters [5-7]. 
Electrochemical advanced oxidation processes are environmentally friendly technologies capable of producing $\cdot \mathrm{OH}$ (hydroxyl radicals). In the electrochemical oxidation process, the solutions are decontaminated through the direct reaction of pollutants with $\cdot \mathrm{OH}$ radicals formed at the anode surface during the electrolysis process [8]. As we all know, the anode material plays an important role in the electrochemical processes for the pollutant removal efficiency [9-11]. Many electrode materials, such as $\mathrm{Ti} / \mathrm{RuO}_{2}$, nano- $\mathrm{ZnO}, \mathrm{IrO}_{2}$, diamond and tungsten trioxide-exfoliated graphite composite [12-16], have been employed to the electrochemical degradation of different organic pollutants. Despite the high efficiency for organic compounds degradation, however, such electrochemical processes are usually energy-intensive because of high overpotential and side reactions [17]. This has attracted more researchers in searching for more efficient and specific catalysts. Recently, metal nanoparticles are recognized as high-efficiency catalysts and have been used for organic pollutant degradation. For example, nano-scale $\mathrm{Cu}, \mathrm{Au}, \mathrm{Ag}$ and $\mathrm{Fe}-\mathrm{Ni}$, are known to efficiently catalyze redox reactions with a high stability [18-21].

In this study, a novel Pt/ACF electrode (platinum supported on activated carbon fibers) was prepared by two methods and was used to degrade EDTA. Compared with Pt sheet electrode, the $\mathrm{Pt} / \mathrm{ACF}$ electrode showed an obviously better effect on EDTA and chemical oxygen demand (COD) removal. The structure and morphology of the electrode was studied by scanning electron microscopy (SEM) and nitrogen adsorption. The experimental parameters, including the electrolyte concentration, initial EDTA concentration, current density and initial value of $\mathrm{pH}$, were studied and optimized. The oxidation intermediates were identified by gas chromatography-mass spectrum (GC-MS).

\section{Experimental}

\subsection{Materials and Reagents}

$\mathrm{Na}_{2} \mathrm{SO}_{4}, \mathrm{Na}_{2}$ EDTA $2 \mathrm{H}_{2} \mathrm{O}, \mathrm{H}_{2} \mathrm{SO}_{4}, \mathrm{NaOH}$ and $\mathrm{H}_{2} \mathrm{PtCl}_{6} \cdot 6 \mathrm{H}_{2} \mathrm{O}$, which are commercially available, were used without further purification. Activated carbon fibers (ACF) were obtained from Nantong Senyou Carbon Fiber Company Limited (Nantong, China). Platinum sheet (Pt) electrode was obtained from Tianjin Aida Technology Development Company (Tianjin, China).

\subsection{Electrode Preparation and Characterization}

The detailed procedure for the preparation of the $\mathrm{Pt} / \mathrm{ACF}$ electrode has been presented in previous works [22]. Briefly, ACF was first washed in deionized water, and then boiled in concentrated $\mathrm{HCl}$ solution for three days to remove impurity. Lastly, the ACF was thoroughly rinsed with deionized water to remove residual $\mathrm{HCl}$, and then dried in the oven at $100^{\circ} \mathrm{C}$. Two methods were used for the catalyst preparation: incipient wetness impregnation and electrodeposition. For the conventional impregnation method, an aqueous solution of $\mathrm{H}_{2} \mathrm{PtCl}_{6}$ was used as precursor and two platinum loadings ( $3 \mathrm{wt} \%$ and $5 \mathrm{wt} \%)$ were prepared. A piece of ACF $(1 \mathrm{~cm} \times 1.5 \mathrm{~cm})$ was first soaked in platinum precursor solution to saturate the ACF pores. The wet $\mathrm{ACF}$ was dried under room conditions, then vacuum-dried at room temperature, and finally reduced in a fixed-bed flow reactor with $\mathrm{H}_{2}$ $(30 \mathrm{~mL} / \mathrm{min})$ at $400{ }^{\circ} \mathrm{C}$ for $2 \mathrm{~h}$ to give $\mathrm{Pt} / \mathrm{ACF}$ catalyst. For electrodeposition method, $3 \mathrm{wt} \%$ platinum loadings were prepared (EDPt/ACF), a piece of ACF $(0.1 \mathrm{~g})$ was fixed with electrode holder as cathode, films of metal catalysts were formed on the ACF surface by thoroughly galvanostatic deposition using aqueous $\mathrm{H}_{2} \mathrm{PtCl}_{6}$ solutions of given concentration $\left(0.008 \mathrm{~g} \mathrm{H}_{2} \mathrm{PtCl}_{6} \cdot 6 \mathrm{H}_{2} \mathrm{O}\right.$ in $10 \mathrm{~mL}$ water, Pt content $0.003 \mathrm{~g}$ ) with a current of $1 \mathrm{~A}$. Pt sheet was used as the counter electrode. ACF electrode was placed in the middle of the cell and electrolyte was stirred with magnetic stirrer during electrodeposition.

The prepared electrodes were comprehensively characterized. Specifically, the surface morphology of the ACF, 3\% Pt/ACF, 5\% Pt/ACF and 3\% EDPt/ACF electrodes were characterized using scanning electron microscopy (Sirion200, FEI Ltd., Eindhoven, The Netherlands). Their pore structure was evaluated with the adsorption/desorption isotherms of $\mathrm{N}_{2}$ using an automatic surface 
area and pore analyzer (Tristar II 3020 M, Micromeritics Co., Atlanta, GA, USA). The dispersion of Pt was checked by CO adsorption [23].

\subsection{Electrochemical Experiments}

The Pt/ACF electrode was used as the anode and a titanium plate was used as the cathode. EDTA was selected as the model organic pollutant. Firstly, different electrodes were used to study the effect of electrode type on the EDTA and COD removal. Then, the influencing parameters, including electrolyte concentration $(0.05-0.5 \mathrm{~mol} / \mathrm{L})$, initial EDTA concentration $(100-1000 \mathrm{mg} / \mathrm{L})$, the initial $\mathrm{pH}$ value (3.0-11.0) and current density $\left(10-50 \mathrm{~mA} / \mathrm{cm}^{2}\right)$, were studied with $3 \% \mathrm{Pt} / \mathrm{ACF}$ electrode.

\subsection{Analytical Methods}

Quantitative analysis of EDTA was measured by HPLC method according to the procedure reported by Li et al. [24]. The instantaneous current efficiency (ICE) was calculated on the basis of chemical oxygen demand of the reaction solution, using the following equation [25]:

$$
\mathrm{ICE}=\frac{\left(\mathrm{COD}_{0}-\mathrm{COD}_{\mathrm{t}}\right)}{8 \mathrm{It}} \mathrm{FV} \times 100 \%
$$

In this equation, $\mathrm{COD}_{0}$ and $\mathrm{COD}_{\mathrm{t}}(\mathrm{g} / \mathrm{L})$ are $\mathrm{COD}$ at time intervals. $F$ is the Faraday constant $(96,487 \mathrm{C} / \mathrm{mol}), V$ is the volume of the solution (L), $I$ is the current (A) and $t$ is the reaction time (s).

The degradation products of EDTA were analysed by GC-MS according to the procedure reported by Li et al. [26].

\section{Results}

\subsection{Characterization of Pt/ACF Electrode}

The surface morphology of the prepared $\mathrm{Pt} / \mathrm{ACF}$ electrodes were characterized. Figure 1 shows the SEM images of the black ACF, 3\% Pt/ACF, 5\% Pt/ACF and 3\% EDPt/ACF. As we have reported before [22], the conductivity of ACF is very high because of its network structure. The specific surface area (BET) of blank ACF is $2398 \mathrm{~m}^{2} / \mathrm{g}$, very similar to the value that has been reported [27]. Compared with other supporting materials [28], ACF has much larger surface area. As Table 1 shows, the majority pores of ACF are micropores with the volume being $1.13 \mathrm{~cm}^{3} / \mathrm{g}$. Meanwhile, the micropore volumes of ACF decreased with loading different content of platinum; this decrease might be attributed to the fact that the pores on the ACF were partially filled with platinum. Among all the electrodes, the surface area and micropore volume of 3\% EDPt/ACF are minimum, this is probably due to the fact that pores on the ACF surface were filled with platinum, leading to a metal film (Figure 1). As seen in Figure 1, most of the platinum was uniformly distributed as nano-lattice in $3 \% \mathrm{Pt} / \mathrm{ACF}$, but partial platinum was agglomerated to bulk in 5\% Pt/ACF. As shown in Table 2, when metal loading increased from 3 to $5 \%$, dispersion and Pt area all decreased sharply. However, the particle size increased from 2.1 to $6.5 \mathrm{~nm}$.

Table 1. Structural parameters of blank ACF and the catalysts.

\begin{tabular}{|c|c|c|c|c|}
\hline Catalyst & Preparation Method & BET $\left(\mathrm{m}^{2} / \mathrm{g}\right)$ & $\begin{array}{c}\text { Micropore } \\
\text { Volume }\left(\mathrm{cm}^{3} / \mathrm{g}\right)\end{array}$ & $\begin{array}{l}\text { Micropore Area } \\
\left(\mathrm{m}^{2} / \mathrm{g}\right)\end{array}$ \\
\hline Blank ACF & $\begin{array}{l}\text { Water wash and } \mathrm{H}_{2} \\
\text { reduction }\end{array}$ & 2398 & 1.13 & 1729 \\
\hline $3 \% \mathrm{Pt} / \mathrm{ACF}$ & impregnation method & 1862 & 0.94 & 1347 \\
\hline $5 \% \mathrm{Pt} / \mathrm{ACF}$ & impregnation method & 1360 & 0.66 & 995 \\
\hline $3 \% \mathrm{EDPt} / \mathrm{ACF}$ & electrodeposition method & 896 & 0.47 & 671 \\
\hline
\end{tabular}

BET: specific surface area. 


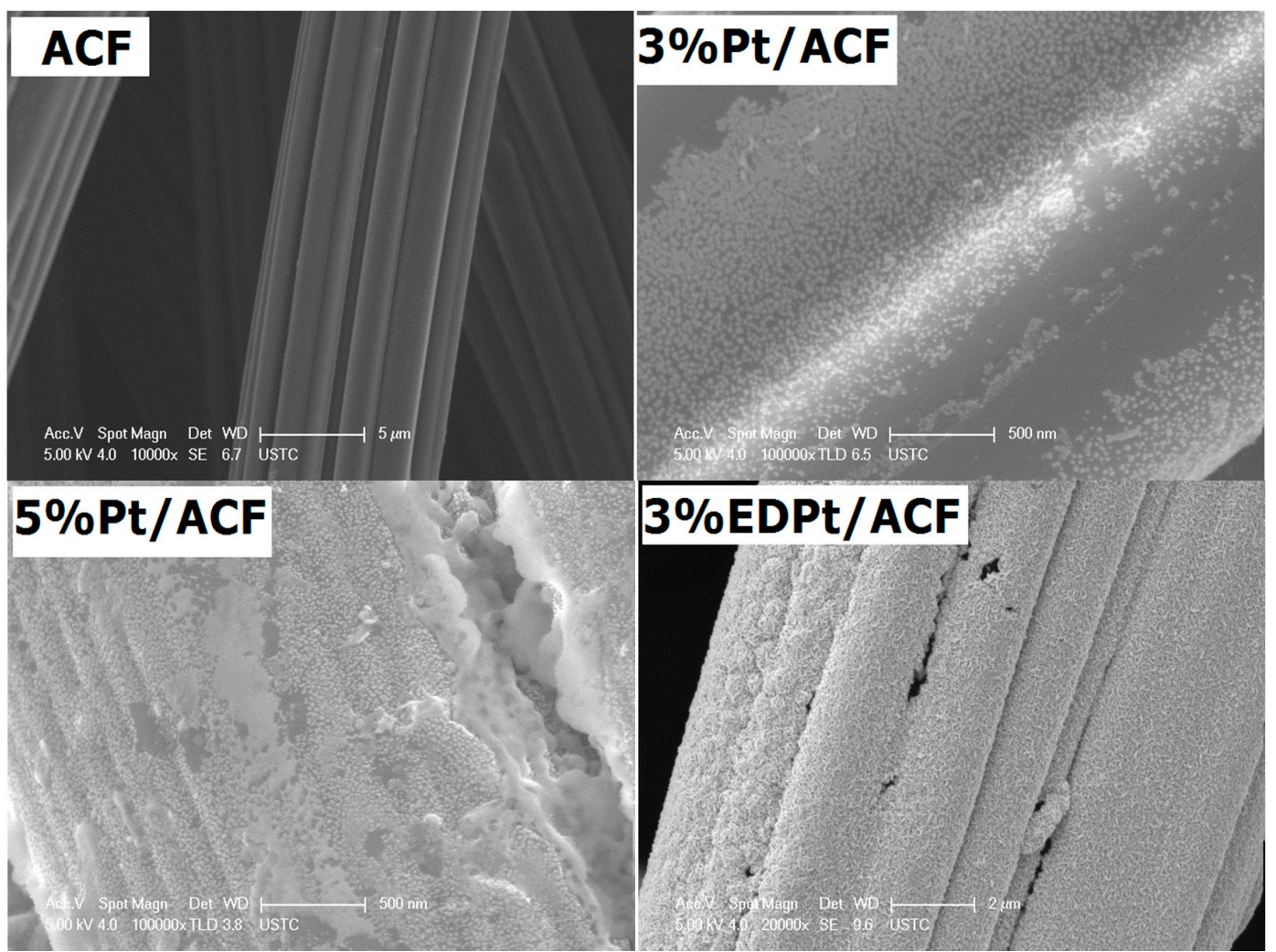

Figure 1. SEM images of the ACF, 3\% Pt/ACF, 5\% Pt/ACF and 3\% EDPt/ACF electrodes. SEM: scanning electron microscopy; ACF: activated carbon fibers.

Table 2. CO adsorption properties and dispersion of Pt.

\begin{tabular}{|c|c|c|c|c|c|}
\hline Catalyst & $\begin{array}{c}\text { CO Adsorption } \\
(\mu \mathrm{mol} / \mathrm{g})\end{array}$ & $\begin{array}{l}\text { Pt Area } \\
\left(\mathrm{m}^{2} \mathrm{~g} / \mathrm{cat}\right)\end{array}$ & $\begin{array}{l}\text { Pt Area } \\
\left(\mathrm{m}^{2} \mathrm{~g} / \mathrm{Pt}\right)\end{array}$ & $\begin{array}{c}\text { Dispersion } \\
(\%)\end{array}$ & $\begin{array}{l}\text { Particle Size } \\
(\mathrm{nm})\end{array}$ \\
\hline $3 \% \mathrm{Pt} / \mathrm{ACF}$ & 83.4 & 4.0 & 134.0 & 54.2 & 2.1 \\
\hline $5 \% \mathrm{Pt} / \mathrm{ACF}$ & 44.8 & 2.2 & 43.1 & 17.5 & 6.5 \\
\hline $3 \% \mathrm{EDPt} / \mathrm{ACF}$ & n.d. ${ }^{a}$ & n.d. ${ }^{a}$ & n.d. ${ }^{a}$ & n.d. ${ }^{a}$ & n.d. ${ }^{a}$ \\
\hline
\end{tabular}

${ }^{a}$ No data can be calculated because pores on the ACF surface were filled with Pt.

\subsection{Effect of Different Electrodes}

To explore the electrochemical oxidation performance of different $\mathrm{Pt} / \mathrm{ACF}$ electrodes, black ACF, $\mathrm{Pt}$ sheet, 3\% Pt/ACF, 5\% Pt/ACF and 3\% EDPt/ACF were prepared to degrade EDTA on condition of the current density, electrolyte concentration, EDTA concentration were $40 \mathrm{~mA} / \mathrm{cm}^{2}, 0.1 \mathrm{~mol} / \mathrm{L}$ and $300 \mathrm{mg} / \mathrm{L}$, respectively. As were shown in Figure 2, with the anodes of Pt sheet, black ACF, 3\% $\mathrm{Pt} / \mathrm{ACF}, 5 \% \mathrm{Pt} / \mathrm{ACF}$ and 3\% EDPt/ACF electrodes, the effects were 26\%, 15\%, 94\%, 75\% and 56\% for EDTA removal after $100 \mathrm{~min}$. While for COD removal, the effects were $16 \%, 5 \%, 60 \%, 51 \%$ and $47 \%$ after $100 \mathrm{~min}$, respectively. Compared with the effects of other electrodes, the removal of EDTA and COD of 3\% Pt/ACF electrode was the best. Meanwhile, the ICE of 3\% Pt/ACF electrode was the highest in the whole process (Figure 2), suggesting that $3 \% \mathrm{Pt} / \mathrm{ACF}$ electrode possessed an excellent performance for the EDTA degradation. 

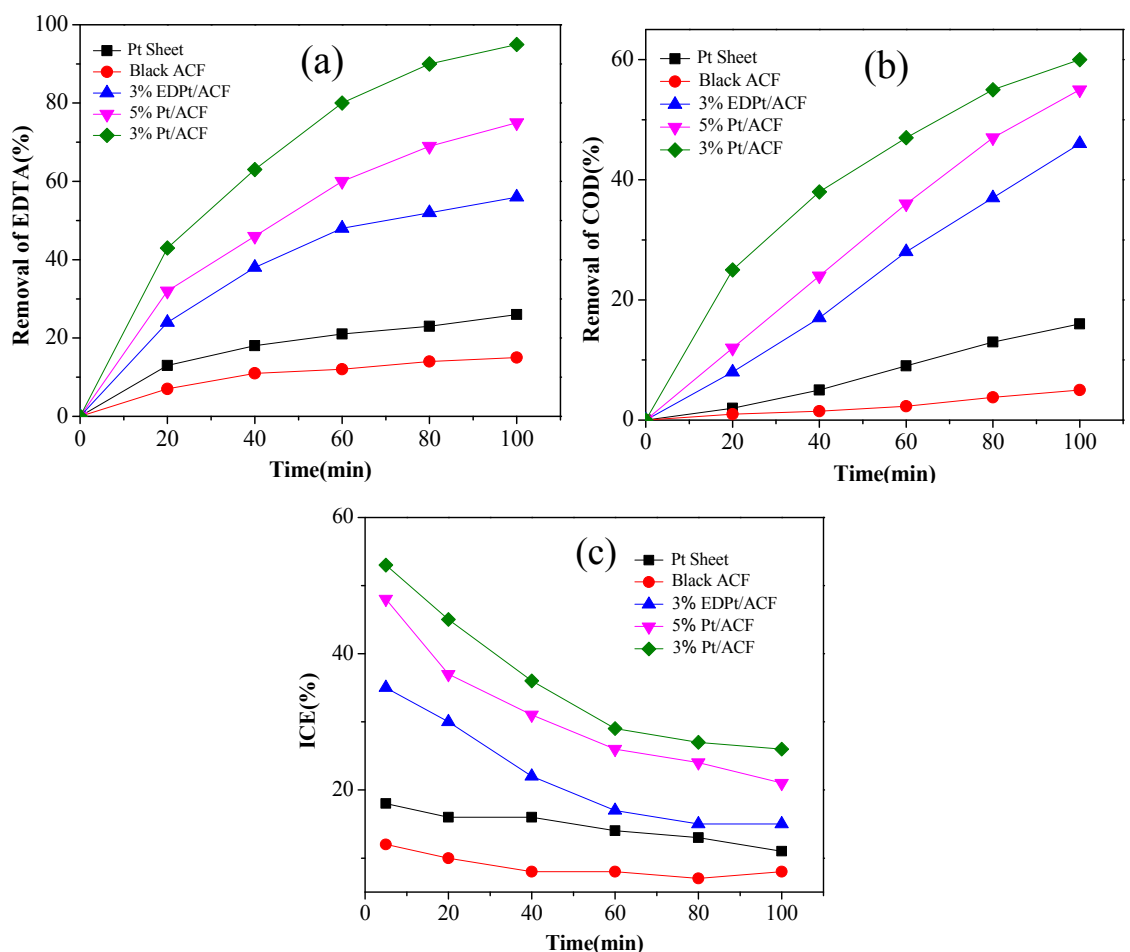

Figure 2. The effect of different electrodes on EDTA removal (a) concentration; (b) COD; (c) ICE (initial pH 5; initial EDTA concentration $300 \mathrm{mg} / \mathrm{L}$; current density $40 \mathrm{~mA} / \mathrm{cm}^{2}$; electrolyte concentration 0.1 mol/L). EDTA: ethylenediaminetetra-acetic acid.

\subsection{Effect of Electrolyte Concentration}

The electrolyte was added to promote the electroconductivity of the EDTA solution [29]. $\mathrm{Na}_{2} \mathrm{SO}_{4}$ was selected as supporting electrolyte varying from $0.05 \mathrm{~mol} / \mathrm{L}$ to $0.5 \mathrm{~mol} / \mathrm{L}$ under the condition of the current density $40 \mathrm{~mA} / \mathrm{cm}^{2}$, pH 5.0 and the EDTA concentration $300 \mathrm{mg} / \mathrm{L}$. As shown in Figure 3, after 100 min electrolysis, the removal of EDTA were $90 \%, 95 \%, 88 \%$ and $69 \%$, and its COD removal were $53 \%, 60 \%, 43 \%$ and $40 \%$ at $\mathrm{Na}_{2} \mathrm{SO}_{4}$ concentration of $0.05,0.1,0.2$ and $0.5 \mathrm{~mol} / \mathrm{L}$, respectively. As a result, the concentration of $\mathrm{Na}_{2} \mathrm{SO}_{4} 0.1 \mathrm{~mol} / \mathrm{L}$ was chosen as an optimal parameter for the rest of this study.
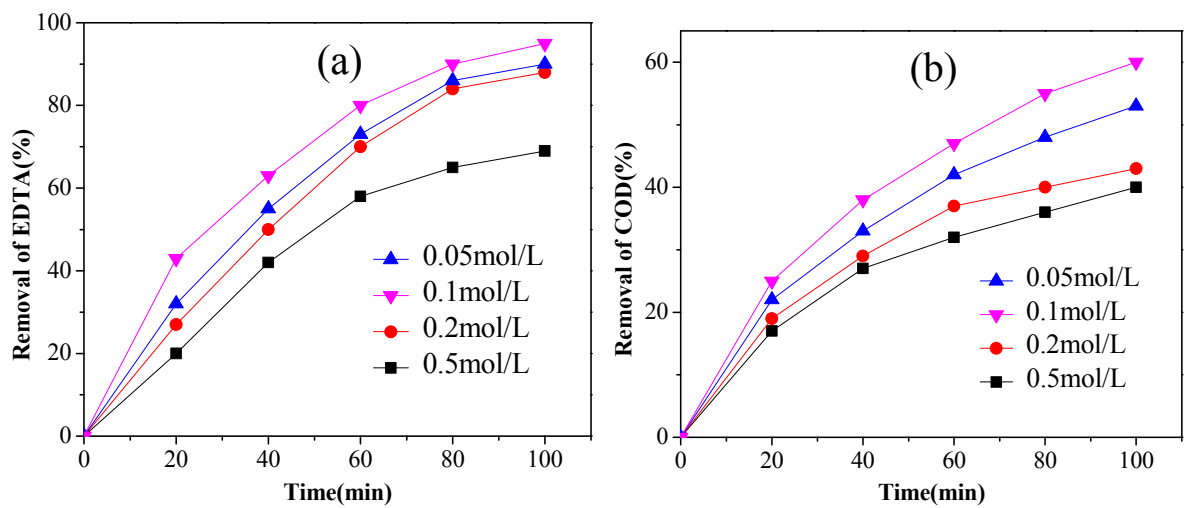

Figure 3. The effect of supporting electrolyte $\left(\mathrm{Na}_{2} \mathrm{SO}_{4}\right)$ concentration on the EDTA removal of (a) concentration, (b) COD (3\% Pt/ACF electrode; initial pH 5.0; initial EDTA concentration $300 \mathrm{mg} / \mathrm{L}$; current density $40 \mathrm{~mA} / \mathrm{cm}^{2}$ ). COD: chemical oxygen demand. 


\subsection{Effect of Initial Concentration of EDTA}

Maintaining the conditions of $\mathrm{pH} 5.0$, current density $40 \mathrm{~mA} / \mathrm{cm}^{2}$, electrolyte concentration $0.1 \mathrm{~mol} / \mathrm{L}$, the effect of initial concentration of EDTA on degradation was investigated, ranging from 100 to $1000 \mathrm{mg} / \mathrm{L}$. As could be observed in Figure 4, the removal rate of EDTA increased at low concentrations (100 to $300 \mathrm{mg} / \mathrm{L}$ ) of EDTA but decreased at higher concentrations (500 to $1000 \mathrm{mg} / \mathrm{L}$ ). The highest value of EDTA removal (95\%) was obtained with $300 \mathrm{mg} / \mathrm{L}$ initial concentration of EDTA, and the highest value of COD removal $(65 \%)$ was obtained with $100 \mathrm{mg} / \mathrm{L}$ of EDTA. So, the level of $300 \mathrm{mg} / \mathrm{L}$ of EDTA was the optimal one.
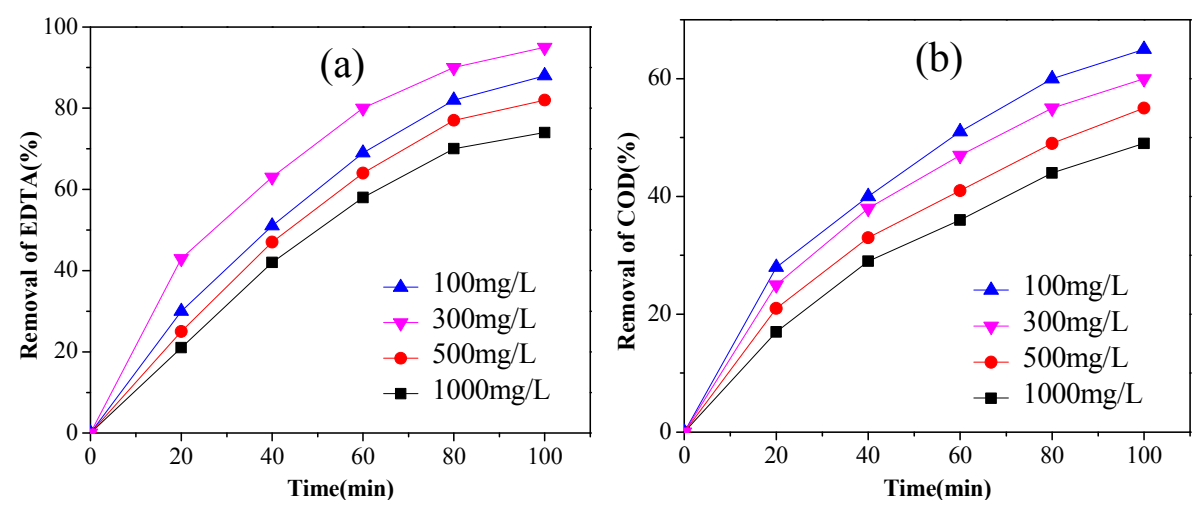

Figure 4. The effect of initial EDTA concentration on EDTA removal (a) concentration; (b) COD ( $3 \% \mathrm{Pt} / \mathrm{ACF}$ electrode; current density: $40 \mathrm{~mA} / \mathrm{cm}^{2}$; electrolyte concentration: $0.1 \mathrm{~mol} / \mathrm{L}$ ).

\subsection{Effect of $p H$}

Different $\mathrm{pH}$ value, varying from 3 to 11 which contain acid environment and alkaline condition, was selected to study the influence of $\mathrm{pH}$ on the removal of EDTA on the condition of current density $40 \mathrm{~mA} / \mathrm{cm}^{2}$, EDTA concentration $300 \mathrm{mg} / \mathrm{L}$, electrolyte concentration $0.1 \mathrm{~mol} / \mathrm{L}$. As was shown in Figure 5 , the efficiency of the electrochemical oxidation process increased in acidic condition, a similar outcome was reported by Han and Wang [28]. EDTA removals were both more than $90 \%$ at initial $\mathrm{pH}$ 3.0 and 5.0 after 100 min of electrolysis. Therefore, $\mathrm{pH} 5.0$ was the optimum $\mathrm{pH}$ value.
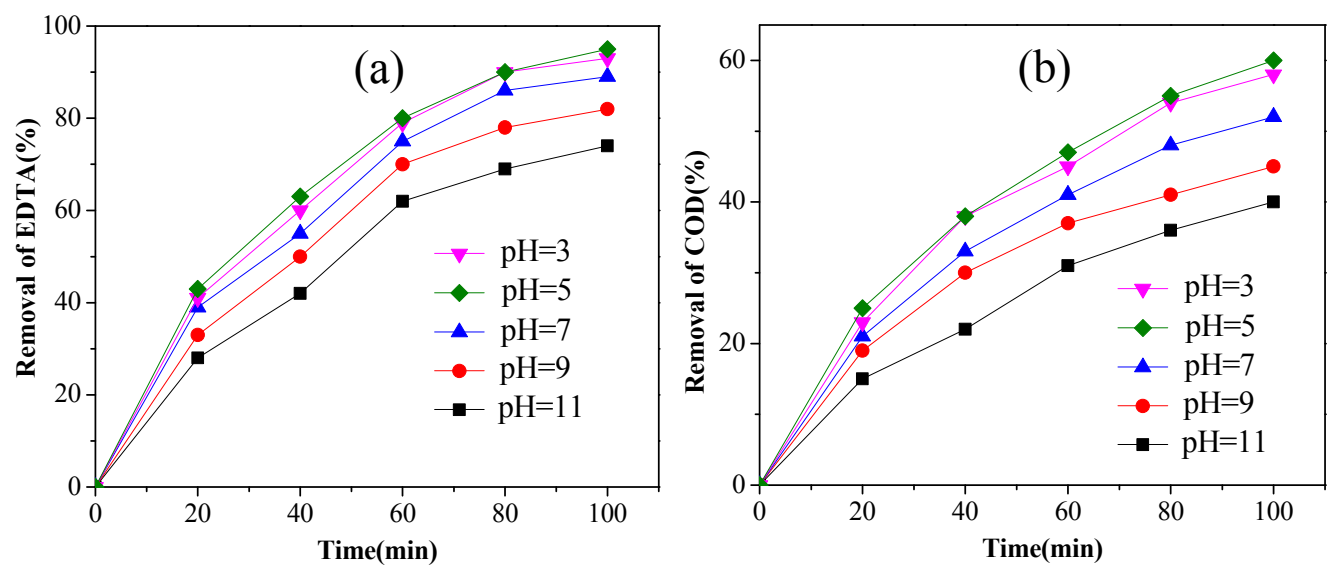

Figure 5. The effect of $\mathrm{pH}$ on the on EDTA removal (a) concentration; (b) COD ( $\%$ Pt/ ACF electrode; EDTA concentration: $300 \mathrm{mg} / \mathrm{L}$; electrolyte concentration: $0.1 \mathrm{~mol} / \mathrm{L}$; current density: $40 \mathrm{~mA} / \mathrm{cm}^{2}$ ). 


\subsection{Effect of Current Density}

To assess the effect of current density on the degradation of $300 \mathrm{mg} / \mathrm{L}$ EDTA, current density ranging from 10 to $50 \mathrm{~mA} / \mathrm{cm}^{2}$ were applied. Figure $6 \mathrm{a}, \mathrm{b}$ showed that the removal of EDTA and COD all enhanced with the increase of current density from 10 to $50 \mathrm{~mA} / \mathrm{cm}^{2}$. Figure $6 \mathrm{c}$ showed that the ICE decreased with increased current density and it decreased rapidly when current density was over $30 \mathrm{~mA} / \mathrm{cm}^{2}$. Therefore, taking into account higher efficiency of degradation and better energy utilization ratio, the current density of $40 \mathrm{~mA} / \mathrm{cm}^{2}$ was chosen in this study.
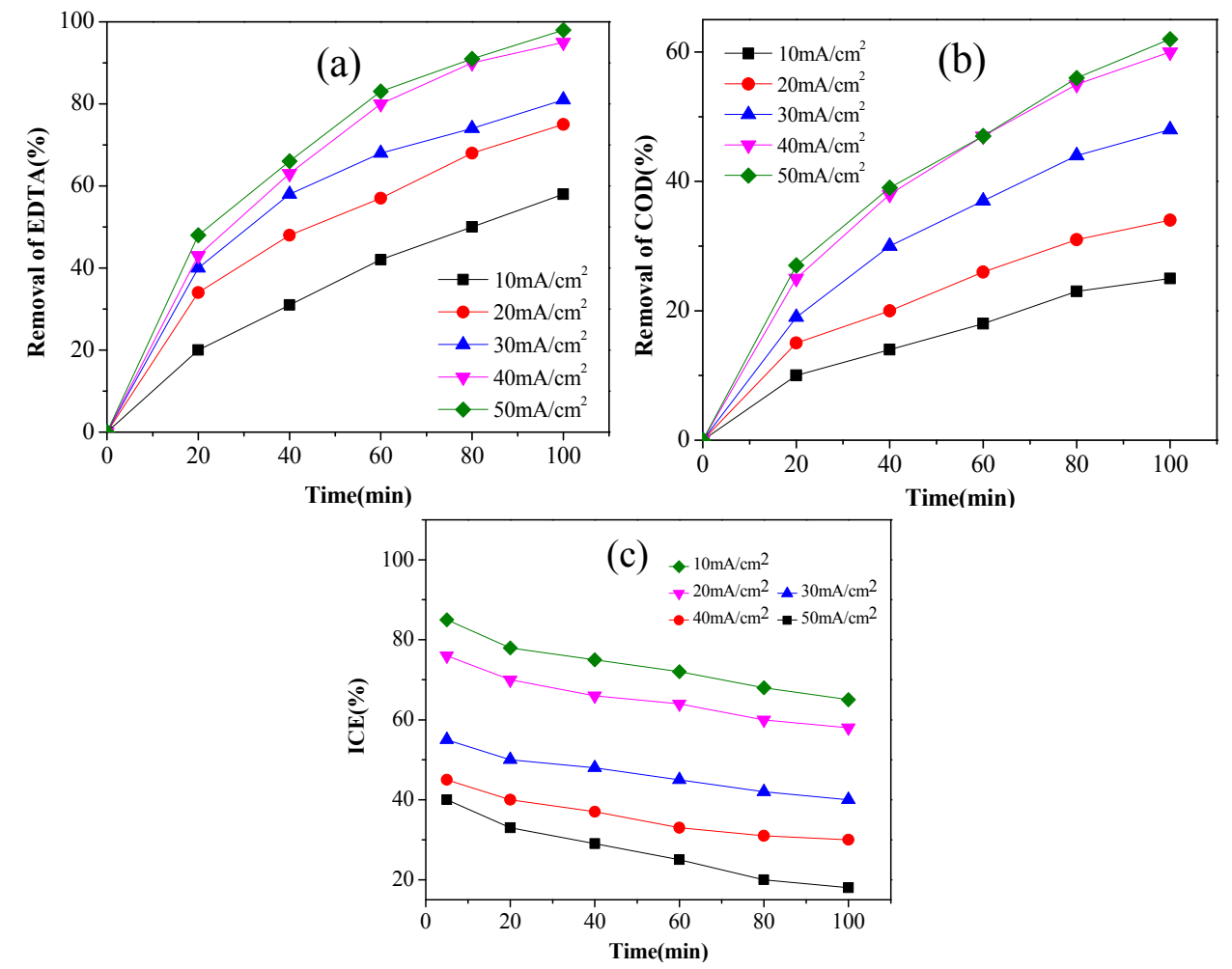

Figure 6. The effect of current density on EDTA removal (a) concentration; (b) COD; (c) ICE ( $3 \%$ $\mathrm{Pt} / \mathrm{ACF}$ electrode; EDTA concentration: $300 \mathrm{mg} / \mathrm{L}$; electrolyte concentration: $0.1 \mathrm{~mol} / \mathrm{L} ; \mathrm{pH}$ 5.0). ICE: instantaneous current efficiency.

\subsection{Identification of the Degradation Products of EDTA}

The intermediate products formed during the degradation process were analyzed by GC-MS technique and the results were shown in Figure 7. In this study, the main oxidation intermediates of EDTA were amino acid. 


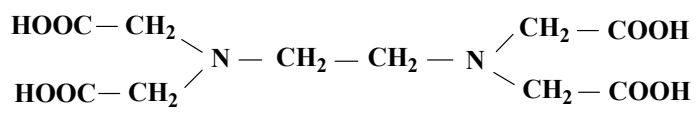

(1)<smiles>NCCNCC(=O)O</smiles>

(2)<smiles>O=C(O)CNCC(=O)O</smiles>

(4)<smiles>O=CNCC(=O)O</smiles>

(6)<smiles>CCNCC(=O)O</smiles>

(3)<smiles>O=C(O)CNC(=O)C(=O)O</smiles>

(5)<smiles>NC(=O)C(=O)O</smiles>

(7)

Figure 7. EDTA and electrochemical oxidation intermediates with $\mathrm{Pt} / \mathrm{ACF}$ electrode.

\section{Discussion}

This work demonstrates that the Pt/ACF can effectively catalyze EDTA degradation. Among various electrodes, the $3 \% \mathrm{Pt} / \mathrm{ACF}$ exhibited the highest EDTA degradation efficiency.

Dispersion of $\mathrm{Pt}$ is summarized in Table 2. It can be seen that both dispersion and metal area decrease sharply with increasing Pt loading from 3 to $5 \%$. However, the particle size shows the opposite trend, these results are consistent with SEM images of the 3\% and 5\% Pt/ACF. These results indicated that the dispersion of $\mathrm{Pt}$ depends strongly on preparation methods and metal loading. In addition, there is a sharp decrease in CO uptake with an increase of Pt loading from 3 to $5 \%$, implying that more active sites are present on $3 \% \mathrm{Pt} / \mathrm{ACF}$. This is probably the primary reason that $3 \% \mathrm{Pt} / \mathrm{ACF}$ exhibits the best catalytic activity among all electrodes.

The degradation of EDTA in aqueous solution depends on various operational parameters such as concentration of supporting electrolyte, initial EDTA concentration, current density and $\mathrm{pH}$. $\mathrm{Na}_{2} \mathrm{SO}_{4}$ are employed for the degradation of EDTA to allow the flow of electrical current. When the concentration of $\mathrm{Na}_{2} \mathrm{SO}_{4}$ increased from $0.05 \mathrm{~mol} / \mathrm{L}$ to $0.1 \mathrm{~mol} / \mathrm{L}$, the conductivity of the solution enhanced and the removal of EDTA and COD increased [30]. However, when $\mathrm{Na}_{2} \mathrm{SO}_{4}$ concentration increased over $0.1 \mathrm{~mol} / \mathrm{L}$, more $\mathrm{SO}_{4}^{2-}$ anions were absorbed on the electrode surface, so the number of active site of electrode minimized, causing a decrease tendency in EDTA degradation [31]. Initial concentration of pollutant is another important parameter for the electrochemical oxidation process. In our study, when the initial concentration of EDTA increased, more substrates are transferred to the surface of electrode, the generation of reactive oxidative species $(\cdot \mathrm{OH})$ are limited [32], so excessive EDTA would decrease the degradation efficiency. Many authors have investigated the effect of initial $\mathrm{pH}$ on the electrochemical oxidation of pollutants in aqueous medium [30,33]. In this study, low $\mathrm{pH}$ was beneficial to degrade the EDTA. This behavior was mainly attributed to the fact that the increase $\mathrm{pH}$ of EDTA solution decreased the hydroxylradical generation [34]. Meanwhile, lower $\mathrm{pH}$ values diminish the oxygen evolution reaction in favor of organic compound oxidation [35]. Current density is an important parameter in the electrochemical oxidation process. The result of this study indicated that high current density could promote the degradation efficiency, because the generation rate of $\cdot \mathrm{OH}$ was enhanced with the current density rose. However, the side reaction like oxygen evolution would also be intensified at a higher current density. Therefore, choosing a suitable current density is very important in galvanostatic oxidation process. 
The GC-MS analysis reveals that the EDTA degradation products were mainly amino acids, some of the compounds have been reported as degradation intermediates of EDTA in the photocatalytic degradation [36] and ozonolysis degradation [37]. Previous studies showed that different intermediates were found in different oxidation processes, some degradation products with functional groups such as carboxylic acids, carbonyl, and amines have been reported [36,38]. Interestingly, the number of intermediates detected in this study is less than that reported previously, possibly because the concentrations of some intermediates are too low to be detected.

\section{Conclusions}

The electrochemical degradation of EDTA over Pt/ACF electrodes was investigated in this study. The major conclusions drawn from this study are summarized as follows:

(1) Two kinds of Pt/ACF electrodes were prepared. The SEM analysis showed that most of the platinum was uniformly distributed as nano-lattice on $3 \% \mathrm{Pt} / \mathrm{ACF}$. The result of $\mathrm{CO}$ adsorption showed that more active sites are present on 3\% Pt/ACF; 3\% Pt/ACF electrode had a better performance for the removal of EDTA and COD than 5\% Pt/ACF and 3\% EDPt/ACF electrode.

(2) The experimental parameters which influenced the removal of EDTA and COD were explored using 3\% Pt/ACF electrode. The optimal removal of EDTA and COD was $94 \%$ and $60 \%$ after $100 \mathrm{~min}$ electrolysis on condition of electrolyte concentration $0.1 \mathrm{~mol} / \mathrm{L}$, initial EDTA concentration $300 \mathrm{mg} / \mathrm{L}$, current density $40 \mathrm{~mA} / \mathrm{cm}^{2}$ and initial $\mathrm{pH}$ value 5.0.

(3) The intermediate generated by electrochemical oxidation of EDTA was detected by GC-MS. It showed that EDTA could be effectively degraded.

Acknowledgments: The authors are grateful for the financial support provided by the research project of the training center of the China Academy of Engineering Physics (2014ZX01), the Open Project of State Key Laboratory Cultivation Base for Nonmetal Composites and Functional Materials (12zxnp08); Projects in the Sichuan Province Science \& Technology Pillar Program (14zs2122), Fundamental Science on Nuclear Wastes and Environmental Safety Laboratory (14zxnk02, 13zxnk02), Doctoral Research Fund Project of Southwest University of Science and out of the office from Technology (15zx7130).

Author Contributions: Wenkun Zhu and Bo Zhao conceived and designed the experiments; Bo Zhao performed the experiments; Tao Mu and Zuowen Hu analyzed the data; Tao Duan and Wenkun Zhu contributed reagents and materials; Bo Zhao wrote the paper.

Conflicts of Interest: The authors declare no conflict of interest. The founding sponsors had no role in the design of the study; in the collection, analyses, or interpretation of data; in the writing of the manuscript, and in the decision to publish the results.

\section{References}

1. Hakem, N.L.; Allen, P.G.; Sylwester, E.R. Effect of EDTA on plutonium migration. J. Radioanal. Nucl. Chem. 2001, 250, 47-53.

2. Toste, A.P.; Polach, K.J.; White, T.W. Degradation of citric acid in a simulated, mixed nuclear waste: Radiolytic versus chemical forces. Waste Manag. 1994, 14, 27-34. [CrossRef]

3. Baldwin, P.N. Evaporation and wet oxidation of steam generator cleaning solutions. Nucl. Technol. 1996, 116, 366-372.

4. Matsuo, T.; Nishi, T.; Matsuda, M.; Izumida, T. Compatibility of the ultraviolet light-ozone system for laundry waste water treatment in nuclear power plants. Nucl. Technol. 1997, 119, 149-157.

5. Haque, M.M.; Smith, W.T.; Wong, D.K.Y. Conducting polypyrrole films as a potential tool for electrochemical treatment of azo dyes in textile wastewaters. J. Hazard. Mater. 2015, 283, 164-170. [CrossRef] [PubMed]

6. Duan, F.; Li, Y.P.; Cao, H.B.; Wang, Y.; Crittenden, J.C.; Zhang, Y. Activated carbon electrodes: Electrochemical oxidation coupled with desalination for wastewater treatment. Chemosphere 2015, 125, 205-211. [CrossRef] [PubMed]

7. Zou, J.; Peng, X.L.; Li, M.; Xiong, Y.; Wang, B.; Dong, F.Q.; Wang, B. Electrochemical oxidation of COD from real textile wastewaters: Kinetic study and energy consumption. Chemosphere 2017, 171, 332-338. [CrossRef] [PubMed] 
8. Panizza, M.; Cerisola, G. Direct and mediated anodic oxidation of organic pollutants. Chem. Rev. 2009, 109, 6541-6569. [CrossRef] [PubMed]

9. Sopaj, F.; Rodrigo, M.A.; Oturan, N.; Podvorica, F.I.; Pinson, J.; Oturan, M.A. Influence of the anode materials on the electrochemical oxidation efficiency. Application to oxidative degradation of the pharmaceutical amoxicillin. Chem. Eng. J. 2015, 262, 286-294. [CrossRef]

10. He, Y.P.; Huang, W.M.; Chen, R.L.; Zhang, W.L.; Lin, H.B. Enhanced electrochemical oxidation of organic pollutants by boron-doped diamond based on porous titanium. Sep. Purif. Technol. 2015, 149, 124-131. [CrossRef]

11. Moreiraa, F.C.; Boaventura, R.A.R.; Brillas, E.; Vilar, V.J.P. Electrochemical advanced oxidation processes: A review on their application to synthetic and real wastewaters. Appl. Catal. B Environ. 2017, 202, 217-261. [CrossRef]

12. Fajardo, A.S.; Seca, H.F.; Martins, R.C.; Corceiro, V.N.; Freitas, I.F.; Quinta-Ferreira, M.E.; Quinta-Ferreira, R.M. Electrochemical oxidation of phenolic wastewaters using a batch-stirred reactor with $\mathrm{NaCl}$ electrolyte and $\mathrm{Ti} / \mathrm{RuO}_{2}$ anodes. J. Electroanal. Chem. 2017, 785, 180-189. [CrossRef]

13. Zhang, C.H.; Tang, J.W.; Chen, P.; Jin, M.Y. Degradation of perfluorinated compounds in wastewater treatment plant effluents by electrochemical oxidation with Nano-ZnO coated electrodes. J. Mol. Liq. 2016, 221, 1145-1150. [CrossRef]

14. Jojoa-Sierra, S.D.; Silva-Agredo, J.; Herrera-Calderon, E.; Torres-Palma, R.A. Elimination of the antibiotic norfloxacin in municipal wastewater, urine and seawater by electrochemical oxidation on $\mathrm{IrO}_{2}$ anodes. Sci. Total Environ. 2017, 575, 1228-1238. [CrossRef] [PubMed]

15. Souza, F.; Quijorna, S.; Lanza, M.R.V.; Sáez, C.; Cañizares, P.; Rodrigo, M.A. Applicability of electrochemical oxidation using diamond anodes to the treatment of a sulfonylurea herbicide. Catal. Today 2017, 280, $192-198$. [CrossRef]

16. Umukoro, E.H.; Peleyeju, M.G.; Ngila, J.C.; Arotiba, O.A. Towards wastewater treatment: Photo-assisted electrochemical degradation of 2-nitrophenol and orange II dye at a tungsten trioxide-exfoliated graphite composite electrode. Chem. Eng. J. 2017, 317, 290-301. [CrossRef]

17. Chen, G.H. Electrochemical technologies in wastewater treatment. Sep. Purif. Technol. 2004, 38, 11-41. [CrossRef]

18. Haider, S.; Kamal, T.; Khan, S.B.; Omer, M.; Haider, A.; Khan, F.U.; Asiri, A.M. Natural polymers supported copper nanoparticles for pollutants degradation. Appl. Surf. Sci. 2016, 387, 1154-1161. [CrossRef]

19. Qu, Y.Y.; Pei, X.F.; Shen, W.L.; Zhang, X.W.; Wang, J.W.; Zhang, Z.J.; Li, S.Z.; You, S.N.; Ma, F.; Zhou, J.T. Biosynthesis of gold nanoparticles by Aspergillum sp. WL-Au for degradation of aromatic pollutants. Physica E 2017, 88, 133-141. [CrossRef]

20. MeenaKumari, M.; Philip, D. Degradation of environment pollutant dyes using phytosynthesized metal nanocatalysts. Spectrochim. Acta A 2015, 135, 632-638. [CrossRef] [PubMed]

21. Kadu, B.S.; Wani, K.D.; Kaul-Ghanekar, R.; Chikate, R.C. Degradation of doxorubicin to non-toxic metabolites using Fe-Ni bimetallic nanoparticles. Chem. Eng. J. 2017, 325, 715-724. [CrossRef]

22. Zhao, B.; Chen, M.Y.; Guo, Q.X.; Fu, Y. Electrocatalytic hydrogenation of furfural to furfuryl alcohol using platinum supported on activated carbon fibers. Electrochim. Acta 2014, 135, 139-146. [CrossRef]

23. Liang, D.; Gao, J.; Wang, J.H.; Chen, P.; Hou, Z.Y.; Zheng, X.M. Selective oxidation of glycerol in a base-free aqueous solution over different sized Pt catalysts. Catal. Commun. 2009, 10, 1586-1590. [CrossRef]

24. Zhou, T.; Lu, X.; Wang, J.; Wong, F.; Li, Y. Rapid decolorization and mineralization of simulated textile wastewater in a heterogeneous Fenton like system with/without external energy. J. Hazard. Mater. 2009, 165, 193-199. [CrossRef] [PubMed]

25. Comninellis, C.; Pulagarin, C. Anodic oxidation of phenol for waste water treatment. J. Appl. Electrochem. 1991, 21, 703-708. [CrossRef]

26. Zhou, T.; Lim, T.T.; Lu, X.H.; Li, Y.Z.; Wong, F.S. Simultaneous degradation of 4CP and EDTA in a heterogeneous Ultrasound/Fenton like system at ambient circumstance. Sep. Purif. Technol. 2009, 68, 367-374. [CrossRef]

27. Pérez, M.C.M.; Lecea, C.S.M.; Solano, A.L. Platinum supported on activated carbon cloths as catalyst for nitrobenzene hydrogenation. Appl. Catal. A 1997, 151, 461-475. [CrossRef] 
28. Li, Z.; Garedew, M.; Lam, C.H.; Jackson, J.E.; Miller, D.J.; Saffron, C.M. Mild electro-catalytic hydrogenation and hydrodeoxygenation of bio-oil derived phenolic compounds using ruthenium supported on activated carbon cloth. Green Chem. 2012, 14, 2540-2549. [CrossRef]

29. Balaji, S.; Kokovkin, V.V.; Chung, S.J.; Moon, I.S. Destruction of EDTA by mediated electrochemical oxidation process: Monitoring by continuous $\mathrm{CO}_{2}$ measurements. Water Res. 2007, 41, 1423-1432. [CrossRef] [PubMed]

30. Dai, Q.Z.; Zhou, J.Z.; Meng, X.Y.; Feng, D.L.; Wu, C.Q.; Chen, J.M. Electrochemical oxidation of cinnamic acid with Mo modified $\mathrm{PbO}_{2}$ electrode: Electrode characterization, kinetics and degradation pathway. Chem. Eng. J. 2016, 289, 239-246. [CrossRef]

31. Chen, J.M.; Xia, Y.J.; Dai, Q.Z. Electrochemical degradation of chloramphenicol with a novel Al doped $\mathrm{PbO}_{2}$ electrode: Performance, kinetics and degradation mechanism. Electrochim. Acta 2015, 165, 277-287. [CrossRef]

32. Dai, Q.Z.; Shen, H.; Xia, Y.J.; Chen, F.; Wang, J.D.; Chen, J.M. The application of a novel $\mathrm{Ti} / \mathrm{SnO}_{2}-\mathrm{Sb}_{2} \mathrm{O}_{3} / \mathrm{PTFE}-\mathrm{La}-\mathrm{Ce}-\beta-\mathrm{PbO}_{2}$ anode on the degradation of cationic gold yellow $\mathrm{X}-\mathrm{GL}$ in sono-electrochemical oxidation system. Sep. Purif. Technol. 2013, 104, 9-16. [CrossRef]

33. Zhong, C.Q.; Wei, K.J.; Han, W.Q.; Wang, L.J.; Sun, X.Y.; Li, J.S. Electrochemical degradation of tricyclazole in aqueous solution using $\mathrm{Ti} / \mathrm{SnO}_{2}-\mathrm{Sb} / \mathrm{PbO}_{2}$ anode. J. Electroanal. Chem. 2013, 705, 68-74. [CrossRef]

34. Lin, H.; Niu, J.F.; Ding, S.Y.; Zhang, L.L. Electrochemical degradation of perfluorooctanoic acid (PFOA) by $\mathrm{Ti} / \mathrm{SnO}_{2}-\mathrm{Sb}, \mathrm{Ti} / \mathrm{SnO}_{2}-\mathrm{Sb} / \mathrm{PbO}_{2}$ and $\mathrm{Ti} / \mathrm{SnO}_{2}-\mathrm{Sb} / \mathrm{MnO}_{2}$ anodes. Water Res. 2012, 46, 2281-2289. [CrossRef] [PubMed]

35. Neto, S.A.; Andrade, A.R. Electrooxidation of glyphosate herbicide at different DSA compositions: $\mathrm{pH}$, concentration and supporting electrolyte effect. Electrochim. Acta 2009, 54, 2039-2045. [CrossRef]

36. Mansilla, H.D.; Bravo, C.; Ferreyra, R. Photocatalytic EDTA degradation on suspended and immobilized $\mathrm{TiO}_{2}$. J. Photochem. Photobiol. A Chem. 2006, 181, 188-194. [CrossRef]

37. Wang, J.G.; Wang, X.K.; Li, G.L.; Guo, P.Q.; Luo, Z.X. Degradation of EDTA in aqueous solution by using ozonolysis and ozonolysis combined with sonolysis. J. Hazard. Mater. 2010, 176, 333-338. [CrossRef] [PubMed]

38. Oviedo, C.; Conireras, D.; Freer, J.; Rodriguez, J. Fe(III)-EDTA complex abatement using a catechol driven fenton reaction combined with a biological treatment. Environ. Technol. 2004, 25, 801-807. [CrossRef] [PubMed] 